\title{
Repetência e reprovação na implementação da escola graduada: emergência e significados históricos
}

\section{Retention and failure in the implementation of the graduated school: emergency and historical meanings}

\author{
Fernanda Cristina Campos da Rocha* \\ Maria Cristina Soares de Gouvea**
}

\begin{abstract}
RESUMO
O artigo busca investigar a emergência da reprovação e da repetência escolar nos primeiros anos de implementação da escola graduada, em Minas Gerais. Procura-se apreender sua ocorrência e os significados que lhes eram atribuídos pelos profissionais da Educação de uma escola primária: o Grupo Escolar Paula Rocha, na cidade de Sabará/MG. Entendemos que tais fenômenos relacionam-se com a organização da escola graduada, no interior de uma cultura escolar fundada na homogeneização das turmas e na complexificação dos processos avaliativos. O corpus documental foi constituído pela legislação educacional, relatórios de direção e inspeção, atas de exames, termos de promoção e livros de matrículas. Verificou-se no período analisado, entre 1907 e 1930, que reprovação e repetência eram concentradas no $1^{\circ}$ Ano escolar, sendo compreendidas como fenômenos distintos. A repetência constituía recurso didático que procurava garantir a aprendizagem diante da extensão do Programa de Ensino e a pouca idade dos estudantes. Estas eram também as justificativas para a reprovação, que incidia mesmo entre alunos aprovados nos exames finais. Verificou-se a criação, pela escola, de estratégias de organização seriada e de avaliação que buscassem garantir a aprendizagem e facilitassem a homogeneização das turmas.
\end{abstract}

Palavras-chave: Educação. Reprovação. Repetência. Avaliação.

${ }^{*}$ Prefeitura Municipal de Belo Horizonte. Belo Horizonte, Minas Gerais. Brasil. E-mail: ffcrocha@yahoo.com.br - http://orcid.org/0000-0003-3457-0653

** Universidade Federal de Minas Gerais. Programa de Pós-Graduação em Educação. Belo Horizonte, Minas Gerais. Brasil. E-mail: crisoares43@gmail.com - http://orcid.org/0000-00018023-1762 


\begin{abstract}
The documentary corpus consisted of educational legislation, inspection reports, exam reports, promotion terms, and enrollment books. It was verified, in the analyzed period between 1907 and 1930, that failure and repetition were understood as distinct phenomena, concentrated in the 1st school year. Repetition was a didactic resource that sought to guarantee to learn, considering the extension of the Teaching Program and the young age of students. These were also the justifications for the failure, which affected even students who passed the final exams. It was verified the creation, by the school, of strategies of serial organization and evaluation that sought to guarantee the learning and to facilitate the homogenization of the classes.
\end{abstract}

Keywords: Schooling. Failure. Repetition. Evaluation.

A reprovação e a repetência escolar constituem questões fulcrais que atravessaram a Educação brasileira ao longo do século XX, tensionando o longo processo de universalização da escola básica. Constituíram-se, também, como marcas do percurso escolar de alunos e alunas, tantas vezes identificadas como fracasso, resultante de uma incapacidade individual. Assumiram, ainda, centralidade na produção acadêmica da Educação, sendo objeto de reflexões de diferentes áreas, como Sociologia, Psicologia, Estatística, Políticas Públicas, as quais vêm ancorando, ainda hoje, ações voltadas para sua superação - o que demonstra a permanência de tais fenômenos. Porém, mesmo que onipresente na história da Educação brasileira, pouco tem sido contemplada nas pesquisas historiográficas ${ }^{1}$.

Pode-se dizer que a produção historiográfica sobre o tema o aborda a partir de questões mais amplas e não como foco central das investigações. Embora seja quantitativamente pouco expressivo, observa-se um interesse crescente nos últimos anos, o que certamente irá repercutir em uma compreensão histórica mais complexa. Nas produções recentes, faz-se predominante um caráter monográfico, em estudos que abordam instituições educativas em períodos históricos distintos (CASON, 2014; LUCHESE, 2014; SILVA, 2014, dentre outros). Destaca-se, ainda, a publicação do dossiê na Revista História da Educação: Um olhar histórico sobre o rendimento escolar, o percurso dos alunos e a repetência, que teve como proposta contemplar a "discussão acerca da presença, dos desempenhos e do movimento dos alunos na escola primária"

1 Cabe destacar as produções de Sérgio Costa Ribeiro (1991) e de Maria Helena Souza Patto (1993). 
(GIL, 2015b, p. 15). Tal dossiê apresentou diversas investigações de grupos de pesquisa nacional sobre o tema, sistematizados e aprofundados, posteriormente, no artigo: Reprovação escolar no Brasil: história da configuração de um problema político-educacional, de Natália de Lacerda Gil (2018).

Busca-se, neste trabalho, contribuir para o avanço do conhecimento sobre o fenômeno, analisando sua emergência no contexto dos primeiros anos de implementação da escola graduada. Para tal, será apresentado um estudo de caso ancorado na análise documental da escrituração escolar de um Grupo Escolar na cidade mineira de Sabará, desde a sua criação, em 1907, até 1919 (data dos últimos registros institucionais acessíveis). Tal estudo insere-se numa pesquisa mais ampla sobre a emergência da reprovação e da repetência na escola pública mineira, entre 1907 (data de criação dos grupos escolares) e 1930, quando se observa um deslocamento no tratamento da questão, fundado no diálogo entre teoria e prática da psicometria, na análise da produção discursiva presente na legislação do período, na escrituração escolar e no periódico Revista de Ensino.

Temos como objetivo, neste texto, compreender como a reprovação e a repetência aparecem na escrituração escolar, buscando analisar, no registro dos processos de avaliação e organização das classes, os sentidos atribuídos aos fenômenos, pelos profissionais da escola.

A análise teve como principal recorte espacial o Grupo Escolar Paula Rocha (GEPR), inaugurado em 1907 e localizado na cidade de Sabará/MG. A realização de um estudo em uma instituição educativa, em particular, possibilitou um olhar mais verticalizado sobre o tema, conferindo visibilidade às estratégias construídas pelos profissionais da escola. As principais fontes abordadas foram as atas de exames escolares, os termos de promoções, os livros de matrículas e os relatórios de diretores e inspetores, além da legislação educacional, acessíveis no acervo das instituições e do Arquivo Público Mineiro. Não iremos, neste texto, abordar aspectos mais amplos, relacionados à cultura escolar da instituição, seus sujeitos (profissionais, alunos e famílias) e a relação com a cidade, nos concentraremos, portanto, nos registros sobre reprovação e repetência.

Iremos, inicialmente, situar a emergência do fenômeno na relação com as práticas de organização das classes pelos profissionais da escola, não previstas na legislação. Posteriormente, iremos analisar os sentidos atribuídos aos termos "repetência" e "reprovação", no estudo dos processos avaliativos da instituição. Verificou-se que, naquele contexto, reprovação e repetência constituíam processos distintos, em que a aprovação nos exames não garantia a promoção para a série subsequente. A reprovação, concentrada no $1^{\circ}$ ano escolar, era compreendida como consequência da extensão dos programas de 
ensino e da pouca idade das crianças. Neste sentido, a repetência constituía um recurso didático de promoção da aprendizagem, numa cultura escolar fundada na homogeneização das classes² .

\section{Homogeneização da aprendizagem e organização das classes}

A prática escolar de avaliar os alunos, por meio de exames públicos realizados por uma banca examinadora e com fiscalização das provas, já estava posta desde o século XIX, permanecendo até o início do século XX, antes mesmo da implantação da escola graduada, havendo a possibilidade de o aluno ser reprovado. Mas o sentido dessa reprovação não era o mesmo, uma vez que não levava o aluno a repetir um ano do ensino. Sabemos, também, que a preocupação maior era com a matrícula escolar e com a frequência dos estudantes, sendo a aprovação nos exames mais uma exceção que a regra (GOUVÊA, 2004).

Em Minas Gerais, a Reforma de 1906 implementou o novo modelo de organização da escola primária, constituindo o momento de "institucionalização e difusão de um novo modelo escolar - das escolas graduadas" (PERES, 2000, p. 15). No interior de uma nova cultura escolar emergem, na documentação analisada, referências cada vez mais presentes à reprovação e repetência, tomadas como fenômenos distintos.

Foi possível visualizar a circulação de discursos entre a escola e a legislação, nos quais identificamos tanto a emergência de discursos na escola, posteriormente presentes nos textos das reformas educacionais, quanto o inverso, quando a legislação pautava as práticas dos grupos escolares. Nesse sentido, no que se refere às avaliações escolares, foi interessante observar que, de um lado, as determinações legais regulavam as práticas avaliativas e, de outro, as soluções encontradas pelo corpo docente influenciavam as mudanças legislativas. Ou seja, observa-se o fluxo entre a norma e as práticas, num processo de dupla direção e, não, apenas, de submissão da prática às normas construídas fora do espaço escolar, de acordo com a dinâmica entre norma e costume discutida por Thompson (1997).

A escola seriada implicava a construção de formas de organização das classes e de mecanismos de avaliação, aprovação e reprovação dos alunos, na concretização de um dos principais pilares da escola graduada, qual seja, a homogeneização. Essa era determinante na classificação dos alunos, provocando

2 Iremos usar, aqui, a denominação de "classe", como aparece nas fontes, para referirmo-nos às turmas e ano escolar, e também como aparece nas fontes, para referimo-nos às series. 
reprovação e repetência, uma vez que, para manter as classes homogêneas por nível de aprendizagem, alguns estudantes deveriam repetir o ano.

Antes da criação do Grupo Escolar na cidade de Sabará, as professoras das escolas isoladas (Gouvêa et al., 2016) lecionavam em classes mistas, ou seja, de meninos e meninas, com idades e níveis de aprendizagem diferentes, em um mesmo espaço, que, em muitos casos, era em uma sala na casa da própria professora. Com a criação do GEPR, a organização dos alunos passou a ser realizada tendo como critério prioritário a distribuição dos estudantes em classes homogêneas, por nível de aprendizagem e, quando possível, por idade e sexo.

A organização das classes, logo após a inauguração do GEPR, em 1907, deu-se da seguinte forma: quatro classes do $1^{\circ}$ Ano, duas classes do $2^{\circ}$ Ano e duas classes do $3^{\circ}$ Ano, não havendo o $4^{\circ}$ Ano Primário. Somente em 1908, o $4^{\circ}$ Ano foi criado, constituído por apenas uma turma mista. Chamou a atenção o fato de o $1^{\circ}$ Ano Primário ser bipartido, ou, dito de outra forma, desdobrado. Isso resultou na existência de quatro classes, cada uma com uma professora diferente. Ou seja, a divisão do $1^{\circ}$ Ano Primário, em 1907, nesse Grupo Escolar, dava-se do seguinte modo: $1^{\circ}$ semestre do $1^{\circ}$ Ano, $2^{\circ}$ semestre do $1^{\circ}$ Ano.

As denominações referidas também foram encontradas, dessa mesma forma, no Programa de Ensino presente na Reforma João Pinheiro (1906). Porém, nesse caso, elas não serviam para definir um nível de escolarização (ano escolar), como no caso do GEPR, mas, sim, para definir o conteúdo a ser ensinado nos dois semestres de cada ano escolar. A divisão dos alunos no $1^{\circ}$ Ano Primário, nessa instituição, estava relacionada com o nível de aprendizagem, a idade e o gênero da criança. As fontes indicam uma combinação entre estes três elementos para a organização das classes. Importa destacar que o primeiro critério era o prioritário. No GEPR, por todo o período analisado, havia classes mistas, com meninos e meninas, o que não pode ser atribuído apenas à insuficiência de alunos para abrir uma classe (possibilidade prevista na legislação), mas, centralmente, a distribuição das crianças era definida pelo nível de aprendizagem. Fica claro, desta maneira, a preocupação com a homogeneização das turmas, discussão presente nos debates pedagógicos, o que indica o destaque que a aprendizagem assumiu naquele período, em conformação com os preceitos da escola graduada.

Observou-se, ao longo do período analisado, uma significativa mudança na organização e denominação das classes, de forma a garantir a homogeneização das turmas. As denominações " $11^{\circ}$ Ano do $1^{\circ}$ semestre" e " 1 'Ano do $2^{\circ}$ semestre" foram utilizadas no GEPR até 1912. Em 1913, houve uma modificação, e as expressões encontradas na documentação passaram a ser "10 Ano atrasado" e " $1{ }^{\circ}$ Ano adiantado". Esta alteração deixa mais claro como ocorria a divisão dos alunos no Grupo, adotando o critério de homogeneização das turmas por nível de aprendizagem. Afinal, com a denominação anterior, que perdurou até 1912, 
pode-se subentender que o desdobramento do $1^{\circ}$ Ano objetivava facilitar a organização dos conteúdos das turmas de acordo com o Programa de Ensino. Já a nova denominação evidencia que o desdobramento era pautado na classificação e homogeneização dos alunos de cada classe.

A originalidade na organização das classes no GEPR, durante o período analisado, demonstra que as determinações legais não eram o único fator observado, convivendo com processos organizativos definidos pela instituição. Afinal, a legislação escolar vigente naquele período não determinou, em nenhum momento, o desdobramento do $1^{\circ}$ Ano em duas classes - uma adiantada e outra atrasada - como ocorria no referido Grupo. Foram as necessidades e dificuldades cotidianas vivenciadas pelo corpo docente, envolvido na rotina escolar do Grupo em questão, que deram origem a práticas criativas, não prescritas legalmente, como a supramencionada ${ }^{3}$. Provavelmente, tal denominação não se restringiu a essa escola, sendo necessário o desenvolvimento de investigações em outras escolas do estado e do País.

A experiência do GEPR evidencia o caráter criativo do sistema escolar, como bem nos alertou Chervel $(1990,1998)$. Por mais que houvesse uma prescrição legal que deveria ser cumprida, havia uma distância entre o que estava presente na Lei e o que, realmente, ocorreu no cotidiano da escola. Isso indica que os professores e a direção escolar atuaram como atores sociais, os quais não apenas reproduziam normas, mas também construíram formas próprias de intervenção e ação diante de uma dada realidade.

\section{Sentidos da reprovação e repetência na escrituração escolar}

Nos primeiros anos de funcionamento do Grupo, observou-se que a principal causa da não conclusão do Primário era a retenção dos alunos no $1^{\circ}$ Ano. Muitos alunos desse Grupo Escolar repetiam várias vezes esse ano do ensino. Na maioria dos casos, gerava-se a desistência da escolarização, ou seja, a evasão escolar, mesmo que temporária, o que ajuda a explicar o maior número de alunos matriculados no $1^{\circ}$ Ano, em todo o período analisado. Segundo Rocha (2008), o $1^{\circ}$ Ano era:

3 Uma experiência similar ocorreu na cidade do Espírito Santo do Pinhal em São Paulo, conforme analisa Rodrigues (2007). O Grupo Escolar Dr. Almeida Vergueiro, em 1912, instituiu mais um ano escolar, o $5^{\circ}$ Ano Primário, o que não estava previsto na legislação. A trajetória dos alunos que concluíssem o Primário nesse Grupo seria: $1^{\circ}$ Ano, $2^{\circ}$ Ano, $3^{\circ}$ Ano, $4^{\circ}$ Ano e $5^{\circ}$ Ano. 
(...) o maior responsável pelas retenções e pelo longo tempo para concluir o primário. O $1^{\circ}$ ano é o "gargalo" do ensino primário. Dos 228 alunos matriculados no Grupo em 1907, 117 repetiram o $1^{\circ}$ ano primário, 40 alunos foram para o $2^{\circ}$ ano primário e as outras 71 crianças saíram do Grupo. Se pegarmos a trajetória do grupo de 1907 a 1916, vemos que o número de crianças matriculadas no $1^{\circ}$ ano primário é sempre muito maior do que as matriculadas nos outros anos do curso (ROCHA, 2008, p. 76).

Gil (2015a, p. 1) parte da compreensão de que nem sempre reprovação e repetência foram assumidas como problema, observando-se "a existência de alunos que não aprendiam, no ritmo esperado, as matérias previstas no programa e o fato de que continuassem na escola mais tempo até que ficasse evidente o domínio dos conteúdos escolares." Para a autora, tais termos assumiam significados distintos:

A reprovação corresponde ao resultado nos exames ou nas avaliações finais que indica que o aluno não teve o desempenho mínimo estabelecido como desejável. A retenção é decorrência dessa reprovação, visto que determina, assumido o modelo de escola seriada, a impossibilidade de o aluno seguir no fluxo normal de uma série a outra. Já a repetência aponta para o fenômeno da permanência na escola dos alunos retidos em determinada série, que vão se submeter a cursá-la novamente (GIL, 2015a, p. 3).

No que se refere à documentação do GEPR, os sentidos de "repetência" e "repetente" não se reduzem aos apresentados pela autora acima. No Grupo, o aluno repetente deveria cursar novamente o mesmo ano do ensino já frequentado. Contudo, a retenção não era decorrente apenas do não aproveitamento no exame final ou da infrequência escolar, sendo observados outros motivos que levavam à retenção. Além disso, a ideia de repetência no GEPR nem sempre estava associada ao fato de repetir as mesmas matérias definidas pelo Programa de Ensino.

Observou-se três motivos para a repetência, com sentidos distintos para o termo "repetente". O primeiro referia-se àquele aluno que, tendo alcançado a média durante o ano, era submetido ao exame final, conforme previsto na legislação. Porém, ao não alcançar a média satisfatória (5), nesse exame, era reprovado, devendo repetir o ano. Nesse primeiro caso, a repetência estava diretamente relacionada à reprovação escolar, devido ao desempenho insuficiente nos exames finais. Em consequência, deveria repetir o ano do curso e os conteúdos escolares. No entanto, outros motivos provocavam a reprovação. 
O segundo motivo para a repetência relacionava-se a não submissão aos exames finais de alunos que não alcançavam a média anual, devendo repetir o ano, como também previsto na legislação. Ambos os sentidos da reprovação se associavam à avaliação do mérito do aluno, sendo sua aprendizagem considerada insuficiente em relação ao conteúdo do programa de ensino da classe cursada.

O terceiro motivo para a repetência naquela instituição era a indicação dos profissionais de ensino de que o aluno permanecesse no mesmo ano escolar, mesmo tendo obtido média anual satisfatória, ou ter sido aprovado no exame final. Nesse caso, repetir o ano não estava associado a um desempenho insuficiente, mas à avaliação de que o estudante seria "muito pequeno", ou que deveria integralizar o Programa de Ensino, repetindo o ano. Tal sentido não estava previsto na legislação, sendo uma prática adotada no GEPR.

Ficou evidente que o conteúdo presente no Programa de Ensino do $1^{\circ}$ Ano Primário não era possível de ser contemplado, em sua totalidade, ao longo de apenas um ano, sendo tal fato percebido como problemático desde a criação do Grupo. Essa era uma tarefa considerada inexequível também nos programas de ensino de outros estados, conforme apontado por Souza (2016), na análise dos programas de ensino de São Paulo.

É necessário ressaltar que havia uma grande preocupação e controle para que o corpo docente seguisse o Programa de Ensino. Em 1916, a diretora Maria José dos Santos Cintra, em relatório enviado ao Secretário do Interior, afirmou, no que concerne à parte pedagógica, estar se esforçando:

\begin{abstract}
[...] em reiteradas recomendações as professoras, por que colocandose cada uma dentro dos limites da matéria que tenha de leccionar, correspondentemente a cada uma das series do programma lectivo, tenha este cabal execução no grupo, sem avanços ou recuos descompassados. O professor deve ser um fiel executor do programa (ARQUIVO PÚBLICO MINEIRO, 1916 b).
\end{abstract}

Em relação à adjetivação do aluno que deveria repetir um ano do ensino, o termo que apareceu em todas as fontes, até a década de 1920, foi o adjetivo "repetente". Em relação àquele não aprovado nos exames finais, os termos utilizados eram "não preparado" e, em alguns casos, "reprovado". Tais termos se faziam presentes nos resumos no final das atas de exames, em que eram apresentados os dados sobre o número de alunos que compareceram, as classificações dos "aprovados" e o registro dos considerados "não preparados" ou "reprovados". 
Nos livros de matrículas, foi possível identificar, no campo destinado às observações, os termos relacionados à prática de promoção do aluno para o ano seguinte, em que alguns novos termos surgiram. Neste campo, era informado a condição do aluno, em relação à promoção para o ano subsequente do ensino, utilizando, quase exclusivamente, os termos "promovido" ou "não promovido". Quanto aos exames, neste campo das observações, aparece apenas se o aluno foi, ou não, aprovado, sem que fosse explicitada a classificação atribuída àquele aprovado em exame. O termo "Inhabilitado" também apareceu no campo destinado às observações dos livros de matrículas. Esse termo só foi utilizado no Grupo para referir-se aos alunos do último ano do ensino, qual seja, o $4^{\circ}$ Ano Primário, considerado não-habilitado a receber o diploma do Curso Primário. Em um relatório de 1912, a diretora afirmou, ao abordar os exames do $4^{\circ}$ Ano, que oito alunos foram "considerados inhabilitados, em vista da insufficiencia das provas que exhibiram" (ARQUIVO PÚBLICO MINEIRO, 1912).

Por fim, é necessário enfatizar que, se por um lado, a repetência escolar nem sempre foi uma preocupação entre o corpo docente do GEPR, ou encarada como um problema, por outro, não podemos afirmar o mesmo em relação ao atraso dos alunos. Essa preocupação era frequentemente demonstrada nos relatórios, visto que apenas os alunos que apresentassem resultados satisfatórios durante o ano seriam submetidos aos exames finais. Em um relatório enviado à Secretaria do Interior, em 1915, o inspetor regional de ensino, Antonio Raymundo da Paixão, destacou: "Argui os presentes em leitura, notando que muitos delles não venceram ainda as difficuldades techinicas dessa disciplina e necessitam de continuadas explicações para, no fim do anno, poderem ser submettidos a exame" (ARQUIVO PÚBLICO MINEIRO, 1915a).

A preocupação com o preparo dos alunos, em termos de aprendizagem, foi verificada no discurso dos inspetores e da direção do GEPR. No relatório do inspetor Arthur Queiroga, de 1916, ele escreveu, a respeito de uma turma de $2^{\circ}$ Ano atrasado: "Poucos alumnos há nesta classe para promoção porque são iniciantes e não puderam [proceder] o mecanismo de leitura"(ARQUIVO PÚBLICO MINEIRO, 1916a).

Nesse trecho, fica evidente a avaliação de que o aluno iniciante, ou seja, novo na escola, não deveria ser promovido para o ano escolar subsequente, devendo cursar duas vezes o mesmo ano. Embora tal situação tenha ocorrido no $2^{\circ}$ Ano, a definição de que um aluno novato deveria repetir o ano restringia-se, quase exclusivamente, ao $1^{\circ}$ Ano. Esse era considerado o ano mais importante do Ensino Primário, a exigir maior atenção dos professores. 


\section{Avaliação, reprovação e repetência na escola graduada}

Tendo em vista a centralidade da reprovação e, principalmente, da repetência no $1^{\circ}$ Ano Primário, buscamos compreendê-las. Algumas hipóteses iniciais foram levantadas, considerando-se especialmente a extensão e o caráter enciclopédico do Programa de Ensino. Tal hipótese relaciona-se à prática, no GEPR, de desdobrar o $1^{\circ}$ Ano em dois, utilizando inicialmente os mesmos termos encontrados no Programa de Ensino $\left(1^{\circ}\right.$ Ano do $1^{\circ}$ semestre e $1^{\circ}$ Ano do $2^{\circ}$ semestre).

Todos os alunos do Ensino Primário deveriam ser submetidos aos exames finais, conforme previsto na Reforma João Pinheiro. Porém, no GEPR, nem sempre isso ocorria. Verificou-se que, especialmente, os "menores" alunos do Grupo, em várias situações, não eram levados a realizar os exames finais, por serem considerados muito "pequeninos", o que ocorria apenas no $1^{\circ}$ Ano Primário.

Assim é que, no GEPR, é possível afirmar que nem sempre repetir o ano significava "incompetência", "inaptidão" ou "incapacidade" do aluno. Além da prática de não submissão de alunos mais novos do $1^{\circ}$ Ano aos exames finais, outra destacou-se. Era comum que alunos referidos como "pequeninos", mesmo se aprovados nos exames, repetirem-no. Um exemplo desse fato ocorreu em 1913, quando a diretora Maria José dos Santos Cintra destacou que alguns alunos alcançaram a média necessária para serem aprovados, porém tiveram de repetir o ano por serem os "menores" do Grupo e também para que o Programa de Ensino fosse totalmente integralizado. Como o $1^{\circ}$ Ano era a base para a continuidade do Ensino Primário, os alunos, segundo a diretora, deveriam repeti-lo. É interessante observar que o aluno deveria repetir o ano e não o conteúdo lecionado, o que reitera que nem sempre a repetência estava associada à sua "inaptidão". Chama a atenção, também, que foi elevado o número de alunos que, mesmo tendo sido aprovados, tiveram de repetir o ano, o que demonstra que a repetência não era compreendida como problemática nos anos iniciais de implantação do modelo da escola graduada, em Minas Gerais.

Situações similares foram encontradas em outros grupos escolares, conforme observado na análise de alguns exemplares do Jornal Minas Geraes. Foi o caso do Primeiro Grupo Escolar da Capital, em 1911, na classe masculina do $1^{\circ}$ Ano, regida pela professora Josina de Lima e Silva. Naquela ocasião, 11 alunos, mesmo tendo demonstrado aproveitamento nos exames finais, sendo aprovados, tiveram de repetir o ano (JORNAL MINAS GERAES, 1911, p. 5). Os motivos apresentados para a repetência foram parecidos com os do GEPR. 
Isso posto, fica claro que o aluno repetente nem sempre era aquele que não obtinha o desempenho esperado pelos professores do GEPR. Assim, não é possível considerar, a priori, que, em todos os casos, a repetência escolar fosse compreendida como problema na instituição, naquele período histórico. $\mathrm{Na}$ realidade, essa prática de os "pequenos" repetirem o ano constituía-se um recurso docente de aprimoramento da aprendizagem, possibilitando integralizar o extenso Programa de Ensino.

Vale ressaltar que os discursos fundados numa Psicologia nascente já se faziam presentes nos registros das Escolas Normais, do corpo docente, das autoridades e especialistas educacionais. Embora os termos "maduro" ou "maturidade" não apareçam claramente nas fontes escolares, ficou evidente que essa ideia era expressa no termo "crianças pequeninas", ou "de pouca idade", constituindo fator de repetência, mesmo para os aprovados no exame. O trecho do relatório de inspeção técnica, de 1913, evidencia as afirmações:

É um desdobramento, pode-se dizer da classe, isto é, um agrupamento de pequeninas, a quem cabe o ensino leve, a educação preliminar para efeitos da adaptação à escola. D. Maria José é hábil e está bem à frente de sua classe. Não julga dever submeter a exames os seus pequenos (ARQUIVO PÚBLICO MINEIRO, 1913).

Nessa situação, a professora defendeu a ideia de não levar suas alunas "pequeninas" a exames, indicando que elas deveriam repetir o $1^{\circ}$ Ano Primário. Do mesmo modo, não é possível considerar que a repetência, nesse caso, fosse percebida como problema e estivesse associada à reprovação das crianças nos exames finais. $\mathrm{O}$ motivo da retenção estava associado à sua pouca idade, sendo necessário maior tempo para a adaptação no Grupo Escolar.

Este mesmo relatório produzido pelo inspetor regional Arthur Queiroga, em 1913, traz outras informações relevantes para se pensar a reprovação e a repetência no GEPR, em especial no $1^{\circ}$ Ano Primário. A classe que a professora regia, na ocasião da visita do inspetor, em 1913, era o "10 anno mixto", com a matrícula de 64 alunos, estando presentes 38 alunos no dia da visita. Segundo o inspetor, a classe era quase a "escola maternal do Grupo Paula Rocha, com os alunos os menores da terra [...]. Tem poucos novos e muitos repetentes, esperando ella poder passar para o $2^{\circ}$ ano $1 / 3$ dos alunos freqüentes" (ARQUIVO PÚBLICO MINEIRO, 1913). Algumas questões em torno deste trecho merecem destaque. 
Primeiramente, o termo utilizado pelo inspetor para referir-se ao aluno que repetiu o $1^{\circ}$ Ano foi "repetente". Foi possível observar que a maior parte dos alunos não foi submetida a exames no ano anterior, uma vez que eram considerados os menores do Grupo, sendo essa a prática adotada na instituição. A justificativa de que os alunos eram "muito pequenos" demonstrava a preocupação do corpo docente com a especificidade de crianças mais novas, consideradas despreparadas para a submissão à formalidade avaliativa dos exames finais.

A preocupação com a criança pequena também estava presente em outros espaços de circulação do discurso nas primeiras décadas do século XX. Na Revista do Ensino, por exemplo, destacam-se alguns artigos que demonstram um cuidado com as crianças pequenas que frequentavam as escolas. Em 1928, Arthur Furtado escreveu acerca do horário escolar, defendendo um horário diferenciado para os alunos do $1^{\circ}$ Ano Primário: "Os trabalhos escolares para os alunos do $1^{\circ}$ anno nunca devem exceder de três horas, empregado o resto do tempo em jogos e exercícios educativos e recreio" (REVISTA DO ENSINO, 1928, p. 2).

Assim é que, na análise da documentação, verifica-se que a retenção de alunos, especialmente no $1^{\circ}$ Ano de ensino não era vista como um problema, sendo defendida pelos professores, independentemente do desempenho nos exames. Nessa direção, foi criado pelo Grupo mais um $1^{\circ}$ Ano Primário. Com isso, a trajetória escolar do aluno era estendida, sendo previsto que um aluno deveria cursar, no mínimo, duas vezes esse Ano de ensino.

Cabe destacar também que, na década de 1910, os dados sobre a repetência ou reprovação não faziam parte do repertório estatístico publicado pelo governo mineiro. Sendo assim, o Grupo não teria problema em relação às taxas de repetência, uma vez que ainda não era numericamente contabilizadas pelo Estado. Apenas em 1917, segundo Caldeira-Machado e Rocha (2015, p. 71), na Revista História da Educação, "os registros sobre aprovações são apresentados por ano do ensino, do $1^{\circ}$ ao $4^{\circ}$ Ano, entretanto, não é possível identificar, pelo número de aprovados, aqueles alunos que são repetentes". É importante observar que, com a Reforma de 1906, a partir de 1910, seria possível, idealmente, ter alunos que tivessem cumprido o fluxo estabelecido pela legislação, ou seja, quatro anos para realizar o Ensino Primário. A sistematização dos dados, em 1917, indica uma estabilização do sistema de escola graduada, o que permitia o registro da trajetória completa ideal do aluno.

Pode-se inferir que o problema, para a escola, se localizava nem tanto na repetência, mas na reprovação. A importância do ritual do exame, a sua visibilidade e o seu caráter público expunham não apenas o aluno, mas também o professor e a instituição à avaliação, o que não ocorria com a repetência. A decisão de não submeter as crianças "muito pequenas" ao processo de avaliação reforça a centralidade dos exames e a tensão que marcava sua realização. 
Outra informação importante que o trecho do inspetor Arthur Queiroga nos traz é a demonstração de confiança da professora e do inspetor de que seria promovida para o $2^{\circ}$ Ano a maior parte da turma, por conter um grande número de repetentes. Sendo assim, a chance de esses alunos avançarem seria maior. Essa crença também foi demonstrada em outros documentos, bem como em diferentes trechos do relatório do inspetor.

Além da classe citada, o inspetor escolar também visitou a classe feminina de $1^{\circ}$ Ano, regida pela professora Maria José de Azeredo Coutinho. Segundo o inspetor, a turma também era de repetentes e, por isso, seus alunos seriam candidatos à promoção para o $2^{\circ}$ Ano. Porém, a professora esperava aprovar para a série subsequente apenas um terço ou metade da turma.

A respeito das questões apresentadas, algumas merecem destaque. A primeira é que a grande maioria das professoras que lecionavam na turma do $1^{\circ}$ Ano de "repetentes" eram as mais antigas do Grupo, consideradas as melhores da instituição, "competentes e dedicadas", conforme indica a escrituração escolar. Todas eram professoras normalistas. Ao analisar os relatórios dos diretores e inspetores, constatamos a importância dada ao $1^{\circ}$ Ano Primário, sendo considerado a "pedra angular" ou a "pedra de toque" do Ensino Primário e o mais importante da trajetória escolar. Assim, era natural que as consideradas melhores professoras ficassem responsáveis por esse Ano do ensino. Lembramos que a legislação previa que a professora, preferencialmente, deveria acompanhar a turma pelos quatro anos do Ensino Primário. No entanto, isso não constituía uma prioridade no GEPR, pois as docentes mais bem-avaliadas permaneciam lecionando para o $1^{\circ}$ Ano. Tal dado reforça a importância da aprovação nos exames, sendo as turmas repetentes não consideradas como "inferiores", tal como se afirmou posteriormente.

\section{Construção da seriação na escola graduada}

Em 1907, ano da inauguração do GEPR, o inspetor técnico Arthur Queiroga, ao visitar o Grupo de Sabará, enviou à Secretaria do Interior um relatório, em que escreveu:

Nas visitas que realizei, guiado pela regra do bom methodo, e pelo interesse que me inspira o ensino inicial, procurei, antes de outras, as classes infantis - os primmeiros annistas -, esses que são a pedra de 
toque para avaliarmos os effeitos da reforma, integralmente aplicada com efficacia, vigor e segurança de methodos e processos, captados no alto estudo e na experiencia de uma temporada escolar (ARQUIVO PÚBLICO MINEIRO, 1907. Grifo nosso).

Ainda acerca da importância dada ao $1^{\circ}$ Ano Primário no GEPR, a diretora Maria Jose dos Santos Cintra escreveu na ata de exames, referente ao ano de 1913, a seguinte consideração:

Os demais alumnos deste ano em numero de 135 revelaram grande aproveitamento conforme se vê das declarações exaradas pelas bancas examinadoras nas respectivas listas de chamada. Como, porem, no seu entender, o primeiro anno constiue a pedra angular de todo o ensino, foram as citadas bancas de parecer que devem estes continuar no mesmo primeiro anno, afim de integralizarem as materias nelle consignadas (ARQUIVO PÚBLICO MINEIRO, 1913. Grifo nosso).

As duas expressões destacadas nas fontes supracitadas foram encontradas nos relatórios de inspetores e diretores e nas atas de exames do GEPR. A primeira expressão "pedra angular" refere-se à denominação da primeira pedra colocada no desenvolvimento de uma construção, ou seja, é a pedra que serve de base, o alicerce. A pedra angular determina a colocação das outras pedras. Nesse sentido, a expressão foi empregada para designar aquilo que era fundamental, imprescindível, a base, nesse caso, o $1^{\circ}$ Ano Primário. Já a expressão "pedra de toque", utilizada para se referir ao $1^{\circ}$ Ano, foi usada no sentido de que ele serviria para avaliar os efeitos da Reforma. Lembremos de que o $1^{\circ}$ Ano era o responsável pela aprendizagem da leitura e da escrita, aspecto valorizado no período.

Destaca-se, ainda, o fato de que, no período republicano, a alfabetização constituía fator de destaque, relacionada à conquista da cidadania e superação do atraso do País. Ou seja, o $1^{\circ}$ Ano era considerado o mais importante, a base do Ensino Primário. Portanto, o aluno não poderia prosseguir nos estudos enquanto não tivesse incorporado todos os conteúdos necessários, previstos na legislação, uma vez que tais conteúdos seriam a base para o prosseguimento do ensino. Isso pode ser uma das explicações para a maior repetência neste Ano do ensino. 
O que se observou no GEPR foi que grande parte dos alunos permanecia, aproximadamente, quatro anos no $1^{\circ}$ Ano Primário. Um aluno novato no $1^{\circ}$ Ano tendia a repetir e, em muitos casos, repetia seguidamente esse Ano do ensino. Isso mostrou que a repetência tendia a ocorrer seguidamente. Esse dado só foi observado no $1^{\circ}$ Ano Primário. Em outros anos do ensino $\left(2^{\circ}\right.$ ao $\left.4^{\circ}\right)$, embora também houvesse reprovação e repetência escolar, estas não tinham a mesma recorrência nem o mesmo sentido.

A repetência fazia parte da trajetória de escolarização dos alunos, sendo naturalizada pelos profissionais da Educação naquele período. A preocupação era voltada para a integralização dos conteúdos previstos no Programa de Ensino, garantindo a aprendizagem, ainda que acarretasse diversas reprovações ou repetências escolares.

Uma solução encontrada para o alto número de reprovações e repetências no $1^{\circ}$ Ano Primário foi a organização, utilizada pelo corpo docente do Grupo, para a composição das classes escolares, durante todo o período aqui analisado. Já é notório que, com a instituição dos grupos escolares, a organização da escola graduada pautava-se "na classificação homogênea dos alunos, na existência de várias salas de aula e vários professores" (SOUZA, 1998, p. 15). Na base, estava o ensino simultâneo, no qual o professor ensinava, ao mesmo tempo, um número maior de alunos, diferentemente do que ocorria com o método individual, ainda utilizado nas escolas isoladas.

Em relação às nomeações dadas às turmas de $1^{\circ}$ Ano, cabe destacar que a de "atrasados" não estava relacionada ao fato de os alunos terem sido reprovados ou repetido o ano, mas aos alunos novatos, com menor idade e que ainda não tinham frequentado o Grupo. Ou seja, o atraso não designava o desempenho insuficiente dos alunos. Em 1918, grande parte da turma do $1^{\circ}$ Ano atrasado repetiu o ano e continuou, em 1919, nesse Ano de ensino.

Nesse caso, ser reprovado no exame e repetir o $1^{\circ}$ Ano Primário não significava repetir o conteúdo previsto pelo Programa de Ensino. Na verdade, os alunos repetiam esse ano do Ensino Primário, mas avançavam para o $1^{\circ}$ Ano adiantado, aprendendo novos conteúdos.

Já a turma do $1^{\circ}$ Ano adiantado era constituída por repetentes. Sendo assim, esperava-se melhor rendimento no fim do ano e, consequentemente, um número maior de promoções e aprovações nos exames escolares. Em 1915, o inspetor regional de ensino, Antonio Raymundo da Paixão, ao visitar a classe do $1^{\circ}$ Ano adiantado, de alunos do sexo masculino, regida pela professora Ida Baptista dos Santos, afirmou que: "[...] havendo examinado os meninos em leitura, observei que o aproveitamento não está de accordo com o tempo de ensino e para esse facto pedi a atenção da colega"(ARQUIVO PÚBLICO MINEIRO, 1915b). 
Como era uma turma que já tinha feito o $1^{\circ}$ Ano, o inspetor não esperava um baixo aproveitamento dos alunos em leitura, mas foi justamente isso que ele encontrou em sua inspeção, sendo, por isso, necessário chamar a atenção da professora.

Vale ressaltar que o percurso previsto no Primário, na instituição, dava-se em, no mínimo, cinco anos e não em quatro, como indicava a legislação: a trajetória escolar de uma criança que nunca tivesse frequentado uma escola anteriormente, nem tivesse sido alfabetizada em casa, e entrasse no Grupo seria de, no mínimo, cinco anos. Isto é, ela passaria pelo $1^{\circ}$ Ano atrasado (ou do $1^{\circ}$ semestre), $1^{\circ}$ Ano adiantado (ou do $2^{\circ}$ semestre), $2^{\circ}$ Ano, $3^{\circ}$ Ano e $4^{\circ}$ Ano.

Importa destacar que ocorreram outras formas de repetência, sendo vistas como problema. Pode-se constatar a questão em alguns relatórios da diretora do GEPR e dos inspetores, que buscavam orientar as professoras para que os alunos tivessem um bom aproveitamento nos exames finais. Isso ocorria, com maior frequência, nos outros anos do ensino, ou seja, do $2^{\circ}$ ao $4^{\circ}$, ou ainda, quando os alunos já haviam repetido o $1^{\circ}$ Ano.

É interessante observar que as estratégias de organização das classes no Grupo Escolar Paula Rocha, em nenhum momento, foram avaliadas como problemáticas pelos inspetores de ensino, mesmo a legislação prevendo quatro anos para a realização do Primário.

Destacou-se o fato de que os menores alunos do Grupo, ou seja, os registrados com 7 e 8 anos, repetirem, com mais frequência, o $1^{\circ}$ Ano Primário. Já aqueles promovidos e aprovados nos exames finais, em sua grande maioria, tinham, em média, 9 anos. Nenhum aluno do GEPR que tenha concluído o Primário em uma trajetória de cinco ou seis anos entrou na instituição com 7 anos de idade. Os alunos mais novos tendiam a repetir mais vezes o $1^{\circ}$ Ano Primário. Os alunos mais velhos, ao contrário, tendiam a repetir menos vezes. Conclui-se que um dos motivos da reprovação e da repetência no $1^{\circ}$ Ano estava relacionado à idade. Os alunos mais jovens matriculados no GEPR, demandariam, na visão dos profissionais de ensino, um tempo para sua adaptação, numa escola definida por processos avaliativos cujo rigor não se fazia presente anteriormente. Além disso, não possuíam ainda as habilidades relacionadas à alfabetização e, por isso, eram reprovados, repetindo o $1^{\circ}$ Ano do Ensino Primário com maior frequência. O inverso também ocorria, pois, os alunos mais velhos, que provavelmente já apresentavam experiência anterior de escolarização ou foram alfabetizados em casa, já chegavam ao Grupo com algum domínio das habilidades necessárias e exigidas para o $1^{\circ}$ Ano e, por isso, tendiam, com menor frequência, a serem reprovados e repetirem esse Ano do ensino. 


\section{Conclusão}

Com o recurso das fontes primárias, foi possível resgatar sentidos históricos distintos para termos como "repetência" e "reprovação", centrais na apreensão do que se definiu, posteriormente, como "fracasso escolar". $\mathrm{Na}$ análise dos discursos daquele período, observa-se que não eram significados como decorrentes de um problema localizado no aluno, mas consequência da organização da escola graduada.

Nesse sentido, a escola buscou construir estratégias organizativas que permitissem viabilizar a aprendizagem. Ainda que se fizessem presentes termos que atribuíssem à "criança pequena" uma necessidade de um tempo maior para a aprendizagem, não existia, nas fontes analisadas, um discurso que atribuísse às diferenças individuais a responsabilidade pela aprendizagem - discurso que se tornou hegemônico, posteriormente.

Assim é que o ideário meritocrático e o caráter seletivo da escola, que ancoraram posteriormente o recurso sistemático à reprovação e à repetência na história da Educação brasileira, não ocupavam centralidade nos discursos e nas práticas das fontes aqui analisadas. A classificação dos alunos, como buscamos demonstrar, estava associada à homogeneização escolar, condição de sucesso do aprendizado.

Ao lançarmos o olhar sobre a reprovação e a repetência, procuramos compreender como esses fenômenos foram produzidos como um problema, sendo naturalizados e incorporados ao modelo da escola graduada e estando presentes ainda nos dias atuais. Ao atribuirmos um caráter histórico a tais fenômenos, foi possível resgatar sentidos distintos.

O deslocamento posterior deu-se, como amplamente estudado ${ }^{4}$, a partir da afirmação e difusão, no interior da escola, do conceito de diferenças individuais, explicativas das diferenças no rendimento dos alunos. Fundadas num determinismo biológico (GOULD, 2014), as teorias psicológicas do período compreendiam que as capacidades mentais seriam inatas, definidas por diferenças individuais, a serem aferíveis em testes padronizados. A concepção da inteligência como atributo individual, aferível e quantificável, tornava possível conferir a cada indivíduo uma posição dentro de uma escala

4 O estudo de Gould (2014) é paradigmático para compreensão do determinismo biológico que fundamenta os testes psicométricos. Para compreensão de sua apropriação pela escola, vide, dentre outras, Souza Patto (1993). Sobre a apropriação e uso de testes psicométricos na escola no Brasil, vide Monarcha(2009) e Campos, Gouvea e Guimarães (2014) 
universal, fornecendo ao conceito de mérito um poderoso arcabouço científico. Este encontrou e encontra, na escola, espaço privilegiado de afirmação, sustentação e reprodução.

Como a investigação aqui apresentada se funda num estudo de caso, faz-se necessário o desenvolvimento de pesquisas historiográficas sobre o tema, que contemplem outros contextos no período de institucionalização da escola graduada ou que confiram visibilidade aos deslocamentos discursivos posteriores.

Cabe também recuperar, nas pesquisas históricas sobre o tema, os sujeitos que viveram tais processos: professores, inspetores e, principalmente, alunos, resgatando como significaram a experiência escolar, em sua pluralidade.

\section{REFERÊNCIAS}

ARQUIVO PÚBLICO MINEIRO. Secretaria do Interior. SI 3270: Relatório de Inspecção techinica, enviado por Arthur Queiroga, dezembro de 1907.

ARQUIVO PÚBLICO MINEIRO. Secretaria do Interior. SI 3412. Relatório apresentado pela directora do Grupo Escolar de Sabará (6 $6^{\mathrm{a}}$ secção), 1912.

ARQUIVO PÚBLICO MINEIRO. Secretaria do Interior. SI 3461: Relatório de Grupos. 1913 ( $6^{a}$ secção). Relatório apresentado pela directora do Grupo Escolar de Sabará, 1913.

ARQUIVO PÚBLICO MINEIRO. Secretaria do Interior. SI 3470: Inspecção techinica do ensino. Relatório da $1^{\text {a a }} 3^{\text {a }}$ circunscripção litteraria, enviado por Arthur Queiroga, 1913.

ARQUIVO PÚBLICO MINEIRO. Secretaria do Interior. SI 3574: Grupos Escolares ( $6^{\mathrm{a}}$ secção). Relatório do inspector regional Antonio Raymundo da Paixão (2 ${ }^{\mathrm{a}}$ circunscripção), 1915a.

ARQUIVO PÚBLICO MINEIRO. Secretaria do Interior. SI 3585: Relatorios (1 $1^{\mathrm{a}}$ a $7^{\mathrm{a}}$ circunscripçao litteraria) (6 $6^{\mathrm{a}}$ secção). Relatório de Antonio Orsini, $1915 \mathrm{~b}$.

ARQUIVO PÚBLICO MINEIRO. Secretaria do Interior. SI 3635: Relatórios de 1916-1 ${ }^{\text {a }}$ a $6^{\mathrm{a}}$ circuncripção (6 $6^{\mathrm{a}}$ seç̧ão). Relatório do inspetor Arthur Queiroga, 1916a.

ARQUIVO PÚBLICO MINEIRO. Secretaria do Interior. SI 3675: Relatórios dos Grupos Escolares. Relatório da directora do Grupo Escolar "Paula Rocha" de Sabará, dezembro de $1916 \mathrm{~b}$.

CALDEIRA-MACHADO, Sandra Maria; ROCHA, Fernanda Cristina Campos da. A invisibilidade dos problemas de percurso dos alunos: dos registros escolares à fabricação das estatísticas educacionais oficiais (Minas Gerais, 1907-1917). História da Educação, Porto Alegre, v. 19, n. 46, p. 53-73, maio/ago. 2015. 
ROCHA, F. C. C. da; GOUVEA, M. C. S. de. Repetência e reprovação na implementação da escola...

CAMPOS, Regina Helena; GOUVEA, Maria Cristina; GUIMARÃES, Paula Davi. A recepção de Binet e dos testes psicométricos no Brasil: contrafaces de uma história. Revista Brasileira de História da Educação, Campinas, v. 14 n. 2, p. 215-242, 2014.

CASON, Silvia Regina. Mapeando trajetórias : os alunos do $1^{\circ}$ Grupo Escolar de Campinas ‘Francisco Glicério’ entre os anos de 1928 a 1935. Dissertação (Mestrado em Educação) - Faculdade de Educação, Unicamp, Campinas, 2014

CHERVEL, André. História das disciplinas escolares: reflexões sobre um campo de pesquisa. Teoria e Educação, Porto Alegre, v. 1, n. 2, p. 177-229, 1990.

CHERVEL, André. La culture scolaire: une approche historique. Paris: Belin, 1998.

GIL, Natália de Lacerda. Reprovação e repetência escolar: a configuração de um problema político-educacional. In: REUNIÃO NACIONAL DAANPED, 37., 2015a, Florianópolis. Anais [...]. Florianópolis: Universidade Federal de Santa Catarina 2015a. p. 1-15

GIL, Natália de Lacerda. Um olhar sobre o rendimento escolar, o percurso dos alunos e a repetência. Hist. Educ. Santa Maria, v. 19, n. 46, maio/ago., 2015 b.

GIL, Natália de Lacerda. Reprovação escolar no Brasil: história da configuração de um problema político-educacional. Revista Brasileira de Educação, Rio de Janeiro, v. 23, 2018.

GOULD, Stephan Jay. A falsa medida do homem. São Paulo: Martins Fontes, 2014.

GOUVÊA, Maria Cristina Soares de. Tempos de aprender: a produção histórica da idade escolar. Revista Brasileira de História da Educação, Campinas, v. 8, p. 265-288, 2004.

GOUVÊA, Maria Cristina Soares de et al. O projeto republicano de instrução e as escolas isoladas urbanas: entre a transitoriedade e a permanência (Belo Horizonte 1906-1927). Revista Brasileira de História da Educação, Maringá, v. 16, n. 2, p. 311-340, 2016.

JORNAL MINAS GERAES. Belo Horizonte: Orgão official dos poderes do estado, 09 e 10 de janeiro de 1911, anno XX, n. 5, p. 3-4.

LUCHESE, Terciane Ângela. Celebrações do saber: exames finais nas escolas da região colonial italiana, Rio Grande do Sul, 1875 a 1930. Revista Diálogo Educacional, Curitiba, v. 14, n. 41, p. 261-285, jan./abr. 2014.

MONARCHA, Carlos. Brasil arcaico, Escola Nova: Ciência, Técnica e Utopia nos Anos 1920-1930. São Paulo: Editora Unesp, 2009

PATTO, Maria Helena Souza. A produção do fracasso escolar: histórias de submissão e rebeldia. São Paulo: T. A. Queiroz, 1993.

PERES, Eliane. Aprendendo formas de pensar, de sentir e agir a escola como oficina da vida: discursos pedagógicos e práticas escolares da escola pública primária gaúcha (1909-1959). 2000. 327 f. Tese (Doutorado em Educação) - Faculdade de Educação, Universidade Federal de Minas Gerais, Belo Horizonte, 2000. 
ROCHA, F. C. C. da; GOUVEA, M. C. S. de. Repetência e reprovação na implementação da escola...

REVISTA DO ENSINO. Belo Horizonte: Imprensa oficial, 1928, anno 4, n. 27, p. 29.

RIBEIRO, Sérgio Costa. A pedagogia da repetência. Estudos Avançados. São Paulo, n. 12 , v. 5, p. 7-21, 1991.

ROCHA, Fernanda Cristina Campos da. A reforma João Pinheiro nas práticas escolares do Grupo Escolar Paula Rocha/Sabará (1907-1916). 2008. 144 f. Dissertação (Mestrado em Educação) - Faculdade de Educação, Universidade Federal de Minas Gerais, Belo Horizonte, 2008.

RODRIGUES, Ana Cláudia de Sousa. Grupo Escolar Dr. Almeida Vergueiro (19121915): a escolarização da infância em Espírito Santo do Pinhal. 2007. 124 f. Dissertação (Mestrado em Educação) - Faculdade de Educação, Universidade de São Paulo, São Paulo, 2007.

SILVA, Carolina Ribeiro Cardoso da. O valor do aluno: vestígios de práticas de avaliação na escola primária (Florianópolis/SC, 1911 a 1963). 2014. 228 f. Dissertação (Mestrado em Educação) - Centro de Ciências Humanas e da Educação, Universidade do Estado de Santa Catarina, Florianópolis, 2014.

SOUZA, Rosa Fátima de. Templos de Civilização: a implantação da escola primária graduada no Estado de São Paulo (1890-1910). São Paulo: Editora UNESP, 1998.

SOUZA, Rosa Fátima de. A configuração das Escolas Isoladas no estado de São Paulo (1846-1904). Revista Brasileira de História da Educação, Maringá, v. 16, n. 2, p. 341-377, 2016.

THOMPSON, Edward Palmer. Senhores e caçadores. A origem da Lei Negra. Tradução de Denise Bottmann. 2. ed. Rio de Janeiro: Paz e Terra, 1997. (Coleção Oficinas da História).

Texto recebido em 16/06/2020.

Texto aprovado em 23/10/2020. 